\title{
A Pesquisa na Formação de Professores de Física: as produções da Biblioteca Digital de Teses e Dissertações no período 2012-2017
}

\section{Research on the Education of Physics Teachers: the production found in the Digital Library of Theses and Dissertations between 2012-2017}

Néryla Vayne Alves Dias ${ }^{1}$

Alberto Albuquerque Gomes ${ }^{2}$

Paulo César de Almeida Raboni²

'Universidade Estadual de Maringá (UEM), Departamento de Ciências, Goioerê, PR, Brasil. Autora correspondente: nvadias2@uem.br

${ }^{2}$ Universidade Estadual Paulista (UNESP), Faculdade de Ciências e Tecnologia, Departamento de Educação, Presidente Prudente, SP, Brasil.

Resumo: Este estudo refere-se a uma pesquisa bibliográfica que teve como objetivo identificar os direcionamentos das pesquisas em nível de mestrado e doutorado no campo da formação de professores de física, disponíveis na Biblioteca Digital de Teses e Dissertações, no período de 2012 a 2017. O corpus de análise se constituiu dos resumos, com busca realizada a partir das palavras-chave ensino de física e formação de professores, tendo como aporte teórico a análise do discurso bakhtiniana. Nossos resultados indicam que as pesquisas vinculadas à formação do professor de física priorizam investigações na formação inicial. No campo da formação continuada mostram-se, prioritariamente, como iniciativas pontuais. Notamos que os pesquisadores se dirigirem ao interlocutor professor a partir de falas autoritárias e prescritivas, indicando como deve ser feito o seu trabalho. Todavia, as parcerias de trabalho de reflexão das possibilidades de superação dos desafios locais permanecem tímidas.

Palavras-chave: Ensino de física; Formação inicial do professor; Formação continuada do professor; Pesquisa bibliográfica.

Abstract: This study refers to bibliographic research, which aimed to identify the orientation in master's and doctoral studies in the field of physics teacher education available in the Digital Library of Theses and Dissertations within the 2012-2017 period. The corpus of analysis consisted of abstracts, with the search conducted for the keywords physics teaching and teacher education, and the theoretical framework was Bakhtinian discourse analysis. Our results indicate that research on physics teacher education prioritizes investigations on initial education. In the field of continuing education, they represent occasional initiatives. We note that researchers address the teacherinterlocutor with authoritarian and prescriptive speeches, pointing at how the work should be done by the latter. However, partnerships for working on reflections about possibilities to overcome particular challenges remain modest.

Keywords: Physics teaching; Teacher initial education; Teacher continuing education; Bibliographic research.

Recebido em: 11/09/2019

Aprovado em: 09/04/2020 


\section{Introdução}

No Brasil, as pesquisas no âmbito do ensino de física tiveram início na década de 1960, sendo gradualmente intensificadas com a criação da Sociedade Brasileira de Física em 1964, e eventos específicos como o Simpósio Nacional de Ensino de Física (SNEF) e o Encontro de Pesquisas em Ensino de Física (EPEF). Na consolidação da área como campo de pesquisa, foi fundamental a criação e expansão dos programas de pós-graduação e de jornais e revistas para divulgação (MOREIRA, 2000; NARDI et al., 2009).

A partir da análise das produções desse período, Pena e Freire (2003) traçaram um perfil da comunidade brasileira de ensino de física, mapeando o desenvolvimento das pesquisas. Perceberam que, na década de 1960, havia pequena produção intelectual, a qual foi intensificada pela promoção do SNEF na década de 1970. Destacam que os trabalhos tinham como focos principais a formação de professores, os métodos de ensino e o ensino experimental. Notaram tímida presença de pesquisas vinculadas à história e filosofia da ciência, à física moderna, às concepções espontâneas, à resolução de problemas, e ausência total de trabalhos que investigassem a física do cotidiano.

Análises como essas, as quais queremos incluir neste trabalho, permitem identificar que as pesquisas sofrem redirecionamentos no decorrer do tempo, com a inclusão de novos temas e a supressão de outros. Evidenciam que essa dinâmica segue influenciada, sobretudo, pelo desenvolvimento do próprio campo de pesquisa, por mudanças na sociedade e por fatores políticos e econômicos.

Atualmente, as pesquisas no ensino de física contemplam temas variados. Os problemas estão vinculados à formação de professores, à relação ensino e aprendizagem, às teorias pedagógicas, ao trabalho docente, às políticas públicas, aos recursos metodológicos, à profissionalidade docente, à alfabetização científica, às tecnologias da informação e comunicação, à história e filosofia da ciência, entre outros (CACHAPUZ, 2014; CAMILLO; MATTOS, 2014; CARVALHO; SASSERON, 2018; MARANDINO, 2005; MARTÍNEZ-AZNAR; RODRÍGUEZ-ARTECHE; GÓMEZ-LESARRI, 2016; NARDI, 2009), na tentativa de compreender por meio dos múltiplos olhares e aspectos, o contexto escolar, a relação professor-alunoconhecimento (de física) e os fatores que influenciam nesta relação. Porém, uma questão se faz pertinente: essas pesquisas têm gerado mudanças na sala de aula?

Anjos (2013) destaca o hiato existente entre o campo da pesquisa em ensino de física e a realidade da prática do professor de física na educação básica. Schnetzler (2000), em análise no campo da formação de professores, afirma que é possível encontrar na literatura inúmeras pesquisas que confirmam os problemas decorrentes da fragilidade na formação de professores. Estes, em geral, apresentam-se despreparados para ministrarem boas aulas. Nesta mesma literatura, pesquisas sugerem como aprimorar tal formação. Todavia, os anos passam, os problemas resistem, repetem-se, revelando que, de fato, pouca coisa se modifica.

A esse conjunto de preocupações presentes nas pesquisas analisadas, somamos outras duas que, neste trabalho, ocupam posição central: a relevância social da pesquisa e o comprometimento com a mudança da realidade. Dimensões que, mesmo almejadas pelos pesquisadores, por vezes não se vislumbram em sua totalidade. Na educação, e no ensino de física em particular, é preciso ter a dimensão de que as mudanças não ocorrem de uma hora para outra. Entretanto, não podemos nos acostumar com a ausência e relegar a pesquisa a fins burocráticos, a número de publicações, a defesa de títulos acadêmicos e a exigências institucionais. 
Perceber como caminha o campo de pesquisa é fundamental. Perceber as lacunas, as tendências, os focos e as principais necessidades. É esse o sentido que adotamos neste trabalho, tendo como objetivo compreender os direcionamentos das pesquisas em nível de mestrado e doutorado no âmbito da formação de professores de física nos últimos anos e identificar o que tem sido produzido na área. Este texto vincula-se a uma pesquisa de doutorado em educação, que tem como objeto o ensino de física e a formação de professores.

Apresentamos, portanto, uma pesquisa de cunho bibliográfico, construída a partir da leitura dos resumos de teses e dissertações depositadas na Biblioteca Digital Brasileira de Teses e Dissertações (BDTD) do Instituto Brasileiro de Informação em Ciência e Tecnologia (IBICT), no período de 2012 a 2017. Como critério de busca utilizamos as palavras-chave ensino de física e formação de professores. Foram selecionados 47 resumos para análise. As análises pautaram-se na teoria do discurso de Mikhail Bakhtin (BAKHTIN, 2003), na intenção de perceber que vozes estão presentes neste campo; perceber de onde falam; quem fala; de que lugar é proferido esse discurso; e que influências poderiam produzir, vislumbrando a mudança da realidade a partir da pesquisa.

Apresentamos, na sequência, o contexto do ensino de física e a formação de professores, seguida da metodologia da pesquisa, análise dos dados e considerações finais.

\section{O Contexto do Ensino de Física e a Formação de Professores}

Segundo Moreira (2000), olhar para a trajetória do ensino de Física no Brasil é olhar para a trajetória do ensino de física em âmbito internacional.

Alguns acontecimentos mundiais foram decisivos no encaminhamento do ensino de física. O fim da década de 1950 marcou a Ciência pela corrida espacial, disputada, principalmente, pela União das Repúblicas Socialistas Soviéticas (URSS) e pelos Estados Unidos. Influências deste marco impulsionaram modificações nos projetos americanos de ensino de Ciências, com um objetivo principal: formar cientistas (SASSERON, 2010).

O Brasil, seguindo os movimentos internacionais, importou materiais didáticos como o Physical Science Study Committee (PSSC) desenvolvido nos Estados Unidos, como um "[...] projeto curricular completo, com materiais instrucionais educativos inovadores e uma filosofia de ensino de Física, destacando procedimentos físicos e a estrutura física" (MOREIRA, 2000, p. 94). O material foi traduzido para o português no início dos anos 1960. Antes do contato com este material, os professores de Física seguiam livros didáticos - atividades experimentais já eram bem vistas - mas o grande condutor do trabalho docente era o livro didático.

A mudança dos livros didáticos para o uso de projetos foi uma mudança de paradigma, que, segundo Moreira (2000), não durou muito. Os projetos representaram um avanço, mas, concomitantemente, introduziram uma lacuna, uma vez que havia muita clareza sobre como se deveria ensinar física "[...] (experimentos, demonstrações, projetos, 'hands on', história da Física, ...) mas pouco ou nada sobre como os alunos aprenderiam essa mesma Física. Ensino e aprendizagem são interdependentes [...]" (MOREIRA, 2000, p. 95). A realidade mostrou que, por mais que se tenham materiais instrucionais para ensinar, a aprendizagem "[...] não é uma consequência natural" (MOREIRA, 2000, p. 95). 
Destaca Moreira (2000) que estes acontecimentos foram impulsionadores de outro paradigma: o da pesquisa em ensino de Física. Logo, consolidaram-se, na década de 1980, as pesquisas relacionadas às concepções alternativas e, posteriormente, à mudança conceitual.

No campo da formação de professores, a expansão da oferta da escolaridade pública no período da ditadura militar acarretou mudanças significativas nos cursos de formação. Passaram então a existir cursos no formato de licenciatura curta, que tinham como objetivo formar em um curto período de tempo (no máximo três anos, por vezes aos fins de semana), profissionais para atuarem nas disciplinas da educação básica. Essa formação aligeirada não teve êxito, pois não correspondia ao conhecimento necessário para as atividades da docência, levando esse modelo à extinção pela Lei de Diretrizes e Bases da Educação, promulgada em 1996. (MAGALHÃES JUNIOR.; PIETROCOLA, 2011).

No caso da física, muitas vezes, profissionais de outras áreas (engenharias, matemática, química, farmácia, etc.) atuaram ministrando aulas, já que não tínhamos profissionais suficientes com a formação específica. Em relatório apresentado ao Conselho Nacional de Educação, Ruiz, Ramos e Higel (2007) informaram que apenas 9\% dos professores atuantes no ensino de física tinham formação específica, os demais eram formados em áreas diversas. Kussuda e Nardi $(2013,2015)$ relacionam a falta de professores de física na educação básica com a pequena quantidade de estudantes que concluem os cursos de licenciatura e a evasão dos professores da profissão na educação básica, considerando as precárias condições de trabalho e os baixos salários.

Essa desvalorização da formação do professor não foi exclusividade do ensino de física. Compareceu em toda educação básica, impulsionada, sobretudo, pela necessidade de ampliação do quadro de docentes. As ideias equivocadas de que ensinar é fácil, e que para ser professor basta ter em mãos um livro didático e manter os estudantes ocupados, trouxeram sérias consequências à profissão docente. No campo da pesquisa, insiste-se em recuperar o prestígio e a valorização da profissão, da qualidade da formação e condições reais de ampliação do capital material, do capital social e do capital cultural dos professores (CACHAPUZ, 2014; ROLDÃO, 2007; SILVA, 2005).

A ampliação das pesquisas não impactou significativamente a promoção da autonomia docente. Os professores, em sua maioria, continuam "obedecendo" a ordens em uma política educacional verticalizada, de cima para baixo, na qual é preciso "por em prática" o que foi definido por especialistas (CHAVES, 2000).

Por outro lado, as deficiências provenientes da formação inicial, somadas a iniciativas pontuais de formação continuada e condições precárias de trabalho, contribuem para diminuir o status profissional docente. Pesquisas, objetivando compreender os conhecimentos dos conteúdos, da didática dos conteúdos dos professores, sobre as crenças e os saberes docentes, sobre o desenvolvimento profissional, sobre a atitude do professor de ciências no exercício da profissão, são relevantes (CARVALHO; GIL PEREZ, 2011; MARCELO, 2009; MARTíNEZAZNAR; RODRÍGUEZ-ARTECHE; GÓMEZ-LESARRI, 2016; TARDIF, 2010). Em uma perspectiva que procuramos corroborar com este trabalho, tais pesquisas representam tentativas de reconhecer e diminuir a distância entre as propostas de mudanças e o que realmente se efetiva na prática em sala de aula. Compreensão essa fundamental para o próprio campo, como para os programas de formação que aspiram à renovação no ensino de ciências e ao aprimoramento da profissionalidade docente. 
Nesse cenário, há um enorme descompasso. A escola não se mostra um espaço legítimo de reflexão e discussão, e a academia, responsável pela pesquisa científica, vestida de neutralidade e competência, é (in)capaz de investigar e apontar os caminhos viáveis para superação dos desafios encontrados pelos professores no exercício da prática (CHAVES, 2000).

Os professores, que vivenciam os desafios e deveriam exercer a autonomia para discussão, reflexão e elaboração de estratégias, não o fazem. Principalmente, porque Ihes falta tempo, espaço; faltam-Ihes condições reais para compreensão do contexto; Ihes faltam iniciativas de parcerias entre universidade-escola para formação profissional; e Ihes faltam reconhecimento quanto à capacidade que os professores têm de tomar iniciativas (por exemplo relativamente à construção do currículo ou às finalidades da educação). O que perpetua na prática, é o professor como aplicador de propostas, ora das pesquisas científicas, ora das políticas públicas, das alterações curriculares e dos programas.

Por outro lado, o pesquisador que está na universidade se distancia da realidade da escola e das dificuldades de implementação desses resultados. Por vezes, excluímos variáveis que influenciam no processo, considerando apenas uma (ou algumas), e depois desejamos que mudanças reais aconteçam na escola.

Neste viés teórico, Chaves (2000, p. 43) chama atenção para a idealização da figura do professor e seu ambiente de trabalho, que "[...] na realidade, o destitui da condição de profissional construtor de sua própria prática", sendo, para o autor, "[...] um dos fatores que contribui para manter a distância entre o que se pensa para e o que se concretiza na educação escolar".

Concordamos, portanto, que os problemas da formação de professores não serão resolvidos a partir de instruções pontuais, em forma de receitas. Faz-se necessário, espaços para a reflexão da realidade, da discussão do coletivo, com vistas ao desenvolvimento da autonomia docente. A pesquisa acadêmica tem que garantir mais do que o grau acadêmico. Para mudanças, o pesquisador deve pensar o todo, valorizar o pluralismo metodológico e melhorar o impacto da pesquisa no ensino (CACHAPUZ, 2014).

\section{Metodologia}

Este estudo teve como objetivo investigar possíveis direcionamentos das pesquisas em nível de mestrado e doutorado no campo da formação de professores de física disponíveis na Biblioteca Digital de Teses e Dissertações (DTBD), no período de 2012 a 2017, e identificar o que tem sido produzido na área.

Tendo como aporte teórico a análise do discurso bakhtiniana, a relevância da pesquisa está em constatar que vozes podem ser ouvidas: quem fala? De onde falam? Que realidades compreenderam? Existem tendências, grupos dominantes, temáticas recorrentes ou lacunas? Intentamos identificar se existe o predomínio de um foco de investigação na formação de professores, seja inicial ou continuada.

A investigação é de origem qualitativa, já que houve preocupação com a interpretação em profundidade dos dados coletados (MARTINS, 2010), e de cunho bibliográfico, por analisar materiais gerados a partir de levantamento. Nosso corpus de análise se constituiu dos resumos das teses e dissertações que versavam sobre a temática, no recorte temporal acima descrito. Para tanto, a busca realizada na BDTD foi a partir de palavras-chave: ensino de física e formação de professores. 
No processo inicial de busca encontramos 67 trabalhos. Após a leitura dos resumos e do refinamento da busca pelo alinhamento (ou não) com o nosso objetivo, selecionamos 47 trabalhos. Na leitura cuidadosa do material, destacamos, sempre que possível ${ }^{1}$, tema, sujeitos, objetivos e, principais resultados. Além disso, atentamo-nos aos programas de pósgraduação, ao orientador(a), e ao tipo da pesquisa - tese ou dissertação. Os dados foram organizados em quadros com a finalidade de facilitar a busca por regularidades, por eventuais lacunas, pela interpretação de direcionamentos das pesquisas e, principalmente, por como elas têm se preocupado em compreender (e quiçá transformar) a realidade estudada.

Os dados da pesquisa foram organizados em categorias, que podem ser interpretadas como vozes, como enunciados, já que Volóchinov (2017, p. 204) declara que "[...] o enunciado se forma entre dois indivíduos socialmente organizados, e, na ausência de um interlocutor real, ele é ocupado, por assim dizer, pela imagem do representante médio daquele grupo social ao qual o falante pertence". Se as pesquisas são destinadas a um interlocutor, então "[...] a palavra é orientada para o interlocutor, ou seja, é orientada para quem é esse interlocutor: se ele é ou não do mesmo grupo social, se ele se encontra em uma posição superior ou inferior em relação ao interlocutor [...]" (VOLÓCHINOV, 2017, p. 203-204). Esses enunciados são direcionados a um destinatário, ele enclausura-se na academia? Ou se amplia para os docentes da educação básica, comprometendo-se com modificações no contexto das práticas e desafios da realidade escolar? Nos casos em que o professor da educação básica está entre os interlocutores da pesquisa, como ele é tratado? Existe uma hierarquia explícita ou tacitamente assumida entre os pesquisadores acadêmicos e professores da educação básica?

\section{Resultados e Discussões}

Percebemos, entre as 47 pesquisas analisadas, o vínculo a três grandes temáticas, que consideramos categorias: (1) Formação inicial de professores de física; (2) Formação continuada de professores de física; (3) Pesquisas sobre os professores de física: análise de suas concepções.

O Quadro 1 apresenta os trabalhos elencados na categoria: Formação Inicial de Professores de Física. A categoria contemplou 24 pesquisas (51,1\% do total de pesquisas), sendo 14 dissertações (D) e 10 teses (T).

Quadro 1 - Categoria: formação inicial de professores de física (24 trabalhos = 51,1\%)

\begin{tabular}{|c|c|c|c|c|c|}
\hline Autor & Título & Orientador & $\begin{array}{l}\text { Instituição/Programa } \\
\text { de Pós-Graduação }\end{array}$ & $\begin{array}{l}\text { Ano de } \\
\text { Defesa }\end{array}$ & $\begin{array}{l}\text { Tipo de } \\
\text { Pesquisa }\end{array}$ \\
\hline ALENCAR, F. P. & $\begin{array}{l}\text { Os laboratórios didáticos em um curso de } \\
\text { física do Parfor no estado do Maranhão }\end{array}$ & FREIRE, M. L. & $\begin{array}{l}\text { Universidade Estadual da } \\
\text { Paraíba, Ensino de Ciências } \\
\text { e Educação Matemática }\end{array}$ & 2016 & D. \\
\hline ALVES, N. V. J. & $\begin{array}{l}\text { Formação inicial de professores: o curso de } \\
\text { licenciatura em física - UNESP/FCT - Presi- } \\
\text { dente Prudente/SP em questão }\end{array}$ & RABONI, P. C. A. & $\begin{array}{l}\text { Universidade Estadual Pau- } \\
\text { lista, Educação }\end{array}$ & 2014 & D. \\
\hline CAMPOS, R. I. & Instrumentação para o ensino de física & CRUZ, F. F.S. & $\begin{array}{l}\text { Universidade Federal de } \\
\text { Santa Catarina, Educação } \\
\text { Científica e Tecnológica }\end{array}$ & 2014 & D. \\
\hline $\begin{array}{l}\text { CASTIBLANCO } \\
\text { ABRIL, O. L. }\end{array}$ & $\begin{array}{l}\text { Uma estruturação para o ensino de didática } \\
\text { da física na formação inicial de professores: } \\
\text { contribuições da pesquisa na área }\end{array}$ & NARDI, R. & $\begin{array}{l}\text { Universidade Estadual } \\
\text { Paulista, Educação para a } \\
\text { Ciência }\end{array}$ & 2013 & $\mathrm{~T}$. \\
\hline
\end{tabular}

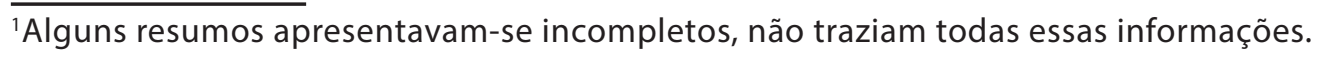




\begin{tabular}{|c|c|c|c|c|c|}
\hline Autor & Título & Orientador & $\begin{array}{l}\text { Instituição/Programa } \\
\text { de Pós-Graduação }\end{array}$ & $\begin{array}{l}\text { Ano de } \\
\text { Defesa }\end{array}$ & $\begin{array}{l}\text { Tipo de } \\
\text { Pesquisa }\end{array}$ \\
\hline CONCHETI, A. F. & $\begin{array}{l}\text { A pluralidade da relação entre a física } \\
\text { e a matemática em um curso inicial de } \\
\text { licenciatura em física }\end{array}$ & LEITE, C. & $\begin{array}{l}\text { Universidade de São Paulo, } \\
\text { Ensino de Ciências }\end{array}$ & 2015 & D. \\
\hline DARROZ, L. M. & $\begin{array}{l}\text { Os impactos do programa institucional de } \\
\text { bolsa de iniciação à docência (PIBID/CAPES) } \\
\text { na formação do professor de física do Rio } \\
\text { Grande do Sul }\end{array}$ & $\begin{array}{l}\text { WANNMACHER, } \\
\text { C. M. D. }\end{array}$ & $\begin{array}{l}\text { Universidade Federal do Rio } \\
\text { Grande do Sul, Educação em } \\
\text { Ciências: Química da Vida } \\
\text { e Saúde }\end{array}$ & 2016 & $\mathrm{~T}$. \\
\hline DECONTO, D. C. S. & $\begin{array}{l}\text { A perspectiva ciência, tecnologia e sociedade } \\
\text { na disciplina de metodologia do ensino de } \\
\text { física: um estudo na formação de professores } \\
\text { à luz do referencial sociocultural }\end{array}$ & OSTERMANN, F. & $\begin{array}{l}\text { Universidade Federal do } \\
\text { Rio Grande do Sul, Ensino } \\
\text { de Física }\end{array}$ & 2014 & D. \\
\hline DEVEGILI, K. L. & $\begin{array}{l}\text { Os projetos temáticos na formação de pro- } \\
\text { fessores de física na UFSC }\end{array}$ & CRUZ, S. M. S. C. & $\begin{array}{l}\text { Universidade Federal de } \\
\text { Santa Catarina }\end{array}$ & 2012 & D. \\
\hline FEDECHEM, R.A & $\begin{array}{l}\text { As múltiplas dimensões no processo formati- } \\
\text { vo de professores no contexto do Programa } \\
\text { Institucional de Bolsas de Iniciação a Docência } \\
\text { (PIBID) Subprojeto Física- UFPR (2009-2012) }\end{array}$ & CAMARGO, S. & $\begin{array}{l}\text { Universidade Federal do Pa- } \\
\text { raná, Educação em Ciências } \\
\text { e em Matemática }\end{array}$ & 2013 & D. \\
\hline GALINDO, M. A. & $\begin{array}{l}\text { O professor da escola básica e o estágio } \\
\text { supervisionado: sentidos atribuídos e a } \\
\text { formação inicial docente }\end{array}$ & ABIB, M. L. V. S. & $\begin{array}{l}\text { Universidade de São Paulo, } \\
\text { Educação }\end{array}$ & 2012 & $\mathrm{~T}$. \\
\hline JESUS, A. C. S. & $\begin{array}{l}\text { Ensino de física na educação de jovens e } \\
\text { adultos: um estudo de caso na formação } \\
\text { inicial de professores }\end{array}$ & NARDI, R. & $\begin{array}{l}\text { Universidade Estadual } \\
\text { Paulista, Educação para a } \\
\text { Ciência }\end{array}$ & 2012 & D. \\
\hline LEITE, A. E. & $\begin{array}{l}\text { O livro didático de física e a formação de } \\
\text { professores: passos e descompassos }\end{array}$ & GARCIA, N. M. D. & $\begin{array}{l}\text { Universidade Federal do } \\
\text { Paraná, Educação }\end{array}$ & 2013 & $\mathrm{~T}$. \\
\hline LEMOS, M. V. & $\begin{array}{l}\text { Dar voltas com professores e licenciandos: } \\
\text { a experiência vivida no ensino de física que } \\
\text { problematiza a carreira docente }\end{array}$ & RODRIGUES, S. C. & $\begin{array}{l}\text { Universidade Federal do } \\
\text { Rio Grande, Educação em } \\
\text { Ciências: Química da Vida } \\
\text { e Saúde }\end{array}$ & 2012 & D. \\
\hline MARINELI, F. & $\begin{array}{l}\text { A realidade das entidades científicas e a } \\
\text { formação de professores de física: uma análise } \\
\text { sociocultural }\end{array}$ & OLIVEIRA, M. P. P. & $\begin{array}{l}\text { Universidade de São Paulo, } \\
\text { Educação }\end{array}$ & 2016 & $\mathrm{~T}$. \\
\hline MULLER, M. G. & $\begin{array}{l}\text { Metodologias interativas de ensino na } \\
\text { formação de professores de física: um estudo } \\
\text { de caso com o peer instruction }\end{array}$ & VEIT, E. A. & $\begin{array}{l}\text { Universidade Federal do } \\
\text { Rio Grande do Sul, Ensino } \\
\text { de Física }\end{array}$ & 2013 & D. \\
\hline ORTIZ, A. J. & $\begin{array}{l}\text { História da ciência e construção do conheci- } \\
\text { mento pedagógico do conteúdo relatividade } \\
\text { na formação de professores de física }\end{array}$ & BATISTA, I. L. & $\begin{array}{l}\text { Universidade Estadual de } \\
\text { Londrina, Ensino de Ciên- } \\
\text { cias e Educação Matemática }\end{array}$ & 2014 & D. \\
\hline RODRIGUES, A. M. & $\begin{array}{l}\text { Movimento e contradição: a disciplina de } \\
\text { prática em ensino de física e formação inicial } \\
\text { de professores de física sob a perspectiva } \\
\text { histórico-cultural }\end{array}$ & MATTOS, C. R. & $\begin{array}{l}\text { Universidade de São Paulo, } \\
\text { Ensino de Ciências }\end{array}$ & 2013 & $\mathrm{~T}$. \\
\hline RODRIGUES, R. F. & $\begin{array}{l}\text { Sobre a estrutura organizacional das } \\
\text { explicações científicas no ensino de física }\end{array}$ & PEREIRA, A. P. & $\begin{array}{l}\text { Universidade Federal do Rio } \\
\text { Grande do Sul }\end{array}$ & 2016 & D. \\
\hline RIBEIRO, D. F. B. & $\begin{array}{l}\text { IFUSP, escola pública e formação de } \\
\text { professores de física: contradição e alienação } \\
\text { no movimento dialético do estágio (não) } \\
\text { supervisionado }\end{array}$ & MATTOS, C. R. & $\begin{array}{l}\text { Universidade de São Paulo, } \\
\text { Ensino de Ciências }\end{array}$ & 2016 & D. \\
\hline SILVA, G. S. F. & $\begin{array}{l}\text { A formação de professores de física na } \\
\text { perspectiva da teoria da atividade: análise } \\
\text { de uma disciplina de práticas em ensino e } \\
\text { suas implicações para a codocência }\end{array}$ & VILLANI, A. & $\begin{array}{l}\text { Universidade de São Paulo, } \\
\text { Ensino de Ciências }\end{array}$ & 2013 & $\mathrm{~T}$. \\
\hline SILVA NETTO, J. & $\begin{array}{l}\text { Complementaridade onda-partícula e } \\
\text { emaranhamento quântico na formação de } \\
\text { professores de física segunda a perspectiva } \\
\text { sociocultural }\end{array}$ & OSTERMANN, F. & $\begin{array}{l}\text { Universidade Federal do } \\
\text { Rio Grande do Sul, Ensino } \\
\text { de Física }\end{array}$ & 2015 & $\mathrm{~T}$. \\
\hline SORPRESO, T. P. & $\begin{array}{l}\text { Energia Nuclear mediante o enfoque Ciência, } \\
\text { Tecnologia e Sociedade na formação inicial de } \\
\text { professores de Física }\end{array}$ & $\begin{array}{l}\text { ALMEIDA, M. J. } \\
\text { P. M. }\end{array}$ & $\begin{array}{l}\text { Universidade Estadual de } \\
\text { Campinas, Educação }\end{array}$ & 2013 & $\mathrm{~T}$. \\
\hline SOUZA, C. A. & $\begin{array}{l}\text { A identidade de licenciandos em física: em } \\
\text { busca de uma caracterização }\end{array}$ & $\begin{array}{l}\text { KAWAMURA, } \\
\text { M. R. }\end{array}$ & $\begin{array}{l}\text { Universidade de São Paulo, } \\
\text { Ensino de Ciências }\end{array}$ & 2012 & D. \\
\hline TESTONI, L. A. & $\begin{array}{l}\text { Caminhos criativos e elaboração de } \\
\text { conhecimentos pedagógicos de conteúdo } \\
\text { na formação inicial do professor de física }\end{array}$ & ABIB, M. L.S. & $\begin{array}{l}\text { Universidade de São Paulo, } \\
\text { Educação }\end{array}$ & 2013 & $\mathrm{~T}$. \\
\hline
\end{tabular}


A formação inicial comparece como tema mais investigado pelas pesquisas, promovido em grande maioria com pesquisas de estudos de caso, desenvolvidas com licenciandos do curso de física. Percebemos que os pesquisadores optam por desenvolver a investigação em disciplinas da licenciatura, como no Estágio Supervisionado, Metodologia do Ensino de Física, Prática de Ensino, Instrumentação para o Ensino, entre outras. Evidencia-se que as pesquisas vinculadas à pós-graduação no âmbito da formação de professores de física têm priorizado o desenvolvimento de pesquisas com licenciandos, que estejam vivenciando o processo de formação inicial.

Inferimos que esta maior recorrência pode estar vinculada ao acesso do pesquisador ao campo de pesquisa, tendo em vista que as pesquisas foram desenvolvidas em instituições públicas. $\mathrm{O}$ acesso do pesquisador aos estudantes e professores da universidade tende a ser um caminho menos tumultuado e burocrático, quando comparados às pesquisas com professores em exercício na educação básica. Outro ponto que pode justificar a priorização das pesquisas na formação inicial é a possibilidade de discutir temas que minimizem o choque de realidade que o professor iniciante tende a enfrentar no início da carreira, fator que pode gerar o abandono da profissão (KUSSUDA; NARDI, 2013; LEONE; LEITE, 2011).

De um modo geral, os pesquisadores vinculam-se a programas de pós-graduação da região sul e sudeste, com destaque para o estado de São Paulo, Rio Grande do Sul e Paraná. Notamos a recorrência de alguns orientadores em mais de uma pesquisa, indicando focos de investigação nos grupos de pós-graduação. As pesquisas foram desenvolvidas em programas de educação, ensino de física, ensino de ciências ou ensino de matemática. Com exceção do ano de $2 \mathrm{2017}^{2}$, foram encontradas pesquisas direcionadas à formação inicial de professores de física em todos os anos, corroborando com a importância dada a esta temática.

A partir de um breve inventário, observamos as seguintes abordagens:

1. Lemos (2012) investigou as influências do interesse pela ciência e do ensino médio na escolha profissional de licenciandos em física; Devegili (2012) trabalhou com os licenciandos a partir de projetos temáticos; Galindo (2012) trabalhou o sentido atribuído ao estágio supervisionado, pesquisando a partir da tríade: estagiário, professor universitário da disciplina de estágio supervisionado e professor da escola; Alves (2014) buscou compreender o processo de formação de um curso de licenciatura em física; Souza (2012) pesquisou sobre a identidade de futuros professores no curso de formação inicial; já Testoni (2013) sobre processos de criação de novos conhecimentos pedagógicos por futuros professores; Rodrigues (2016) analisou explicações científicas de licenciandos; e Marinelli (2016) investigou em âmbito filosófico sobre a realidade das entidades científicas. Observa-se, nesse grupo de trabalhos, o olhar dirigido aos estudantes em processo de formação inicial.

2. Tendo como foco percepções de professores formadores e futuros professores, Ribeiro (2016) intentou pesquisar a compreensão dos professores que acolheram estagiários, relacionando as aulas de regência; Jesus (2012) investigou, a partir da análise do discurso, o imaginário dos futuros professores de física em relação à educação de jovens e adultos; Silva (2013) procurou compreender o processo de tornar-se professor, a partir da disciplina de prática de ensino; Rodrigues (2013) analisou a disciplina de prática de ensino, considerando a configuração dos novos currículos das licenciaturas;

${ }^{2}$ Acreditamos que quando realizamos a busca (durante o primeiro semestre de 2018), ainda não tinham sido depositadas na BTDT todas as pesquisas defendidas em 2017. 
Leite (2013) trabalhou com orientações e discussões sobre o livro didático nos cursos de licenciatura do Sul do Brasil. Observa-se aqui a preocupação com a prática de ensino como espaço de formação de professores.

3. Neste terceiro grupo de trabalhos, destacam-se Concheti (2015) que propôs uma análise das representações em um curso de mecânica a partir da relação entre a física e a matemática; Deconto (2014) pesquisou a relação CTS na formação inicial; na mesma direção Sorpreso (2013) trabalhou elementos da física nuclear em uma perspectiva CTS; Muller (2013) investigou a prática de metodologias interativas no ensino no estágio supervisionado; Campos (2014) analisou projetos desenvolvidos na disciplina de instrumentação do ensino; Fedechen (2013) e Darroz (2014) investigaram as dimensões formativas e a compreensão do processo de formação ambos na perspectiva do Programa de Iniciação à Docência (PIBID); Alencar (2016) sobre os componentes curriculares utilizados pelos laboratórios didáticos, considerando um curso de formação de professores de física do PARFOR; já Ortiz (2014) e Silva Netto (2015) trabalharam com temas da física moderna e contemporânea na formação de professores. Verifica-se aqui um enfoque dirigido principalmente às questões da formação inicial, com pequenas variações que sempre remetem à questão da formação.

Dirigindo nosso olhar para as pesquisas desenvolvidas na formação inicial, depreendemos que, apesar da relevância das temáticas, não podemos perder de vista que muitos licenciandos formados pelas instituições públicas não assumem a carreira docente na educação básica, ou a abandonam nos primeiros anos de profissão. Conforme Kussuda e Nardi (2013), em pesquisa realizada com egressos de uma universidade do estado de São Paulo, dois terços dos sujeitos investigados afirmaram ter abandonado a carreira na educação básica, principalmente pelos baixos salários e as más condições de trabalho. Optaram por caminhar na pós-graduação, trabalhar no ensino superior, ou em outra profissão desvinculada do ensino. Kussuda e Nardi (2015) também destacam o pequeno número de formandos das licenciaturas em física, evidenciando ser esse mais um desafio para que professores efetivamente formados na área assumam a sala de aula, como possibilidade de gerar alguma mudança. Portanto, mesmo que diversas pesquisas sejam realizadas com licenciandos em processo de formação inicial, isso não é garantia que esse aluno assuma aulas na educação básica e faça dessa atividade uma profissão.

Por outro lado, as pesquisas não atingem a totalidade do país na mesma proporção, demonstrando que a concentração de investigações no campo da formação inicial permanece no sul e sudeste. Nossos resultados reforçam as afirmações de Anjos (2013) e Schnetzler (2000), evidenciando que pesquisas desenvolvidas no ensino de física ainda não tem chegado à escola, à sala de aula, para efetivamente contribuir com mudanças na prática docente.

Entendemos que as pesquisas na formação inicial, principalmente em instituições públicas, são de extrema importância; todavia, mostram-se insuficientes para sozinhas modificarem a realidade do ensino de física na educação básica, embora continuem sendo importantes para direcionar o trabalho nos cursos de formação inicial, para pontuar lacunas, contradições, concepções e representações sociais. 
O Quadro 2 apresenta a categoria: Formação continuada de professores de física. Nesta categoria, elencamos os trabalhos que trataram especificamente de investigação na formação continuada de professores de física. Foram encontrados 12 trabalhos - 6 dissertações e 6 teses - que representaram 25,5\% do total de pesquisas selecionadas.

Quadro 2 - Categoria: pesquisas desenvolvidas em nível de Formação Continuada (12 trabalhos $=25,5 \%)$

\begin{tabular}{|c|c|c|c|c|c|}
\hline Autor & Título & Orientador & $\begin{array}{l}\text { Instituição/Programa } \\
\text { de Pós-Graduação }\end{array}$ & $\begin{array}{l}\text { Ano de } \\
\text { Defesa }\end{array}$ & $\begin{array}{l}\text { Tipo de } \\
\text { Pesquisa }\end{array}$ \\
\hline ALMEIDA, D. S. & $\begin{array}{l}\text { Um estudo sobre o uso da lousa digital } \\
\text { interativa como ferramenta didática no ensino } \\
\text { e aprendizagem de física }\end{array}$ & GOYA, A. & $\begin{array}{l}\text { Universidade Tecnológica } \\
\text { Federal do Paraná, Ciências } \\
\text { Humanas, Sociais e da } \\
\text { Natureza }\end{array}$ & 2015 & D. \\
\hline ARAUJO, A. B. & $\begin{array}{l}\text { O uso da experimentação como instrumento } \\
\text { de ensino de física na formação continuada } \\
\text { de professores }\end{array}$ & $\begin{array}{l}\text { OLIVEIRA NETO, } \\
\text { F. A. }\end{array}$ & $\begin{array}{l}\text { Universidade Federal de } \\
\text { Mato Grosso, Ensino de } \\
\text { Ciências Naturais }\end{array}$ & 2015 & D. \\
\hline ELLYAN, J.T. & $\begin{array}{l}\text { Interações dialógicas em práticas investigativas } \\
\text { na sala de aula: experiências de uma professora } \\
\text { de física em (trans) formação }\end{array}$ & JONIS, M. A. J. & $\begin{array}{l}\text { Universidade Federal do } \\
\text { Espírito Santo, Ensino de } \\
\text { Física }\end{array}$ & 2014 & D. \\
\hline LEONEL, A. A. & $\begin{array}{l}\text { Formação continuada de professores de Física } \\
\text { em exercício na rede pública de Santa Catarina: } \\
\text { lançando um novo olhar sobre a prática }\end{array}$ & ANGOTTI, J. A. & $\begin{array}{l}\text { Universidade Federal de } \\
\text { Santa Catarina, Educação } \\
\text { Científica e Tecnológica }\end{array}$ & 2015 & $\mathrm{~T}$. \\
\hline LOPES, L. F. & $\begin{array}{l}\text { O uso de MC em uma abordagem sócio- } \\
\text { interacionista no ensino de Física }\end{array}$ & ARAYA, A. M. O & $\begin{array}{l}\text { Universidade Estadual } \\
\text { Paulista, Faculdade de } \\
\text { Ciências e Tecnologia }\end{array}$ & 2015 & D. \\
\hline $\begin{array}{l}\text { ROEHRING, S. } \\
\text { A. G. }\end{array}$ & $\begin{array}{l}\text { Formação continuada de professores de física: } \\
\text { contradições e (im) possibilidades de transfor- } \\
\text { mação da atividade docente }\end{array}$ & ABIB, M. L.S. & $\begin{array}{l}\text { Universidade de São Paulo, } \\
\text { Ensino de Ciências }\end{array}$ & 2016 & $\mathrm{~T}$. \\
\hline SALES, N. L. L. & $\begin{array}{l}\text { Problematizando o ensino de física moderna } \\
\text { e contemporânea na formação continuada de } \\
\text { professores: uma análise das contribuições dos } \\
\text { três momentos pedagógicos na construção da } \\
\text { autonomia docente }\end{array}$ & LEITE, C. & $\begin{array}{l}\text { Universidade de São Paulo, } \\
\text { Ensino de Ciências }\end{array}$ & 2014 & T. \\
\hline $\begin{array}{l}\text { SANTARELLI, M. } \\
\text { C. I. }\end{array}$ & $\begin{array}{l}\text { O papel da formação continuada de física } \\
\text { na relação de professores com as atividades } \\
\text { experimentais }\end{array}$ & MURAMATSU, M. & $\begin{array}{l}\text { Universidade de São Paulo, } \\
\text { Ensino de Ciências }\end{array}$ & 2014 & D. \\
\hline SANTOS, L. C. A. & $\begin{array}{l}\text { As múltiplas dimensões no processo formati- } \\
\text { vo de professores no contexto do Programa } \\
\text { Institucional de Bolsas de Iniciação a Docência } \\
\text { (PIBID) Subprojeto Física- UFPR (2009-2012) }\end{array}$ & $\begin{array}{l}\text { KAWAMURA, M. } \\
\text { R. D. }\end{array}$ & $\begin{array}{l}\text { Universidade de São Paulo, } \\
\text { Ensino de Ciências }\end{array}$ & 2017 & T. \\
\hline SARTORI, A. F. & $\begin{array}{l}\text { Produção docente de vídeos digitais para o } \\
\text { ensino de física: desafios e potencialidades }\end{array}$ & PICONEZ, S. C. B. & $\begin{array}{l}\text { Universidade de São Paulo, } \\
\text { Ensino de Ciências }\end{array}$ & 2012 & D. \\
\hline SIQUEIRA, M. R. P. & $\begin{array}{l}\text { Professores de física em contexto de inovação } \\
\text { curricular: saberes docentes e superação } \\
\text { de obstáculos didáticos no ensino de física } \\
\text { moderna e contemporânea }\end{array}$ & OLIVEIRA, M. P. P. & $\begin{array}{l}\text { Universidade de São Paulo, } \\
\text { Educação }\end{array}$ & 2012 & T. \\
\hline SOUSA, W. B & $\begin{array}{l}\text { A teoria da transposição didática e a teoria } \\
\text { antropológica do didático aplicadas em um } \\
\text { estudo de caso no ensino da física moderna } \\
\text { e contemporânea }\end{array}$ & RICARDO, E. C. & $\begin{array}{l}\text { Universidade de São Paulo, } \\
\text { Ensino de Ciências }\end{array}$ & 2015 & T. \\
\hline
\end{tabular}

Fonte: elaborado pelos autores.

Nossos dados evidenciam que a pesquisa desenvolvida no âmbito da formação continuada não tem tido a mesma atenção que a formação inicial. Os programas de pósgraduação do estado de São Paulo retêm o domínio do desenvolvimento das pesquisas com 9 trabalhos. Comparecem também duas pesquisas da região sul, uma da região centro-oeste e uma da região nordeste. Cabe destacar que no ano de 2013 não encontramos nenhuma pesquisa relacionada à categoria. 
Os trabalhos vinculados à formação continuada são de extrema relevância, já que investigam e oportunizam momentos de reflexão aos profissionais que de fato estão exercendo a profissão docente na educação básica. No entanto, reconhecemos que pesquisas desta natureza tendem a ser mais burocráticas, por vezes com dificuldades de acesso, e nem sempre recebem a participação efetiva dos sujeitos.

As investigações, em sua maioria, foram desenvolvidas a partir de cursos com professores que estão em exercício, que lecionam a disciplina de física na educação básica. Em relação às temáticas, destacamos:

1. Sartori (2012) trabalhou com a produção de vídeos como material didático, aliando ferramentas da tecnologia para elaborar materiais sobre os conceitos de mecânica; Almeida (2015) trabalhou com curso de formação para professores da rede pública sobre o uso da lousa digital interativa; Siqueira (2012) elaborou sequências didáticas de física moderna e contemporânea junto a um grupo de professores de física; Sales (2014) trabalhou com física moderna e contemporânea, analisando um curso de formação sobre a temática; Sousa (2015) compreendeu a prática docente a partir da vivência em curso de formação continuada sobre física moderna e contemporânea; Ellyan (2014) fez análise de sua trajetória, analisando o próprio percurso formativo de maneira reflexiva; Santarelli (2014), em um estudo desenvolvido com dois professores experientes no ensino médio, objetivou compreender as relações que os professores estabelecem com as atividades experimentais e qual o papel da formação continuada nesta relação; Araújo (2015) teve como foco compreender como os professores de física selecionam critérios para a realização das práticas experimentais, quais os padrões utilizados e as formas de abordagens dos fenômenos como instrumento do ensino; Lopes (2015) trabalhou a organização de conteúdos e avaliação a partir do uso de mapas conceituais e softwares na formação continuada de professores de uma unidade do Sistema Sesi de Ensino; Leonel (2015) desenvolveu uma pesquisa-ação, analisando uma proposta de formação continuada de professores de física, pautada na perspectiva mídia-educação; Roehring (2016) analisou as contradições presentes em um curso de formação continuada de professores de física proposto pelo pacto de fortalecimento do ensino médio; e Santos (2017) fez análise da contribuição do PARFOR para a formação de professores na região do Pará. Como podemos observar nesses trabalhos, com algumas variações, o olhar se dirige majoritariamente a aspectos relativos a formação continuada de professores em serviço.

As pesquisas na formação continuada (ou permanente) demonstram grande potencial para mudanças efetivas, principalmente, por terem a oportunidade de refletir sobre a realidade vivida pelos professores, seus desafios, inseguranças, necessidades formativas, etc. Todavia, isso nos sugere que as pesquisas devam ser fundadas a partir de parcerias com grupos de pesquisa. Das pesquisas analisadas, Santarelli (2014), Sartori (2012) e Leonel (2015) indicam caminhar nessa direção.

Nos demais casos, percebemos a predominância de pesquisas pontuais. Com a elaboração de cursos realizados para coleta de dados e que se encerram em um curto período de tempo.

A justificativa para esse tipo de prática nos sugere que o curto período de tempo, destinado à conclusão do mestrado, favorece a execução de pesquisas pontuais. Contudo, mesmo que a investigação obrigatoriamente tenha um período limitado, pensamos que 
os grupos de pesquisas nas universidades devam desenvolver projetos permanentes de formação continuada. Iniciativas na direção de valorização do professor da educação básica e na parceria, não para ditar o que ele deve fazer, mas para juntos desenvolverem estratégias para superação dos problemas locais.

O quadro 3 apresenta a categoria: Pesquisas sobre formação de professores de física: concepções. Aqui, elencamos as pesquisas que perquiriram sobre os professores, na tentativa de compreender suas concepções. Foram encontrados 12 trabalhos -8 dissertações e 4 teses - que representaram cerca de $23,4 \%$ do total de pesquisas selecionadas.

Quadro 3 - Pesquisas sobre os professores de física: concepções (11 trabalhos = 23,4\%)

\begin{tabular}{|c|c|c|c|c|c|}
\hline Autor & Título & Orientador & $\begin{array}{l}\text { Instituição/Programa } \\
\text { de Pós-Graduação }\end{array}$ & $\begin{array}{l}\text { Ano de } \\
\text { Defesa }\end{array}$ & $\begin{array}{l}\text { Tipo de } \\
\text { Pesquisa }\end{array}$ \\
\hline BARCELLOS M. E. & $\begin{array}{l}\text { Um estudo sobre o uso da lousa digital } \\
\text { interativa como ferramenta didática no ensino } \\
\text { e aprendizagem de física }\end{array}$ & $\begin{array}{l}\text { KAWAMURA, M. } \\
\text { R. D. }\end{array}$ & $\begin{array}{l}\text { Universidade de São Paulo, } \\
\text { Ensino de Ciências }\end{array}$ & 2013 & $\mathrm{~T}$. \\
\hline GARCIA, L. V. & $\begin{array}{l}\text { Conhecimento e currículo: problematizando } \\
\text { a licenciatura em física }\end{array}$ & $\begin{array}{l}\text { KAWAMURA, M. } \\
\text { R. D. }\end{array}$ & $\begin{array}{l}\text { Universidade de São Paulo, } \\
\text { Ensino de Ciências }\end{array}$ & 2015 & $\mathrm{~T}$. \\
\hline LOPES, A. M. & $\begin{array}{l}\text { Professores de física: práticas e subjetividades } \\
\text { no processo de ensinar }\end{array}$ & BAROLLI, E. & $\begin{array}{l}\text { Universidade Estadual de } \\
\text { Campinas, Faculdade de } \\
\text { Educação }\end{array}$ & 2012 & D. \\
\hline MAÇIEL, R. R.. & $\begin{array}{l}\text { A astronomia nas aulas de física: uma } \\
\text { proposta de utilização de unidades de ensino } \\
\text { potencialmente significativas (UEPS) }\end{array}$ & BORGES, B. W. & $\begin{array}{l}\text { Universidade Federal de } \\
\text { Santa Catarina, Mestrado } \\
\text { Profissional em Ensino de } \\
\text { Física }\end{array}$ & 2016 & D. \\
\hline $\begin{array}{l}\text { MENDES, G. H. } \\
\text { G. I.. }\end{array}$ & $\begin{array}{l}\text { Matematização e ensino de física: uma } \\
\text { discussão de noções docentes }\end{array}$ & BATISTA, I. L. & $\begin{array}{l}\text { Universidade Estadual de } \\
\text { Londrina, Ensino de Ciências } \\
\text { e Educação Matemática }\end{array}$ & 2014 & D. \\
\hline SABINO, A. R. & $\begin{array}{l}\text { Saberes docentes desenvolvidos na inserção } \\
\text { de física moderna no ensino médio: um estudo } \\
\text { de caso }\end{array}$ & OLIVEIRA, M. P. P. & $\begin{array}{l}\text { Universidade de São Paulo, } \\
\text { Educação }\end{array}$ & 2015 & D. \\
\hline $\begin{array}{l}\text { SCHMIEDECKE, } \\
\text { W. G. }\end{array}$ & $\begin{array}{l}\text { A história da ciência nacional na formação e } \\
\text { na prática de professores de física }\end{array}$ & PORTO, P. A. & $\begin{array}{l}\text { Universidade de São Paulo, } \\
\text { Ensino de Ciências }\end{array}$ & 2016 & $\mathrm{~T}$. \\
\hline SILVA, E. da S. & $\begin{array}{l}\text { A transposição didática no ensino de física: o } \\
\text { aquecimento global como objeto de estudo }\end{array}$ & $\begin{array}{l}\text { ALMEIDA, A. C. } \\
\text { P. C. }\end{array}$ & $\begin{array}{l}\text { Universidade Federal do } \\
\text { Pará, Educação em Ciências } \\
\text { e Matemática }\end{array}$ & 2012 & D. \\
\hline $\begin{array}{l}\text { SILVA JUNIOR, } \\
\text { O.P.. }\end{array}$ & $\begin{array}{l}\text { O mirabolante mundo das partículas } \\
\text { elementares: uma sequência didática para } \\
\text { professores de física }\end{array}$ & ARAYA, A. M. O. & $\begin{array}{l}\text { Universidade Estadual Pau- } \\
\text { lista, Mestrado Profissional } \\
\text { em Ensino de Física }\end{array}$ & 2015 & D. \\
\hline SILVA, M. A. da. & $\begin{array}{l}\text { O fazer e o pensar dos professores de física } \\
\text { egressos do MECM: contribuições das } \\
\text { tecnologias digitais na formação continuada }\end{array}$ & $\begin{array}{l}\text { MOITA, F. M. G. } \\
\text { S. C. }\end{array}$ & $\begin{array}{l}\text { Universidade Estadual da } \\
\text { Paraíba, Ensino de Ciências } \\
\text { e Matemática }\end{array}$ & 2012 & D. \\
\hline SOUZA, L. P.. & $\begin{array}{l}\text { Um olhar sobre o ensino de física na } \\
\text { perspectiva do Enem }\end{array}$ & SOUZA, D. N. & $\begin{array}{l}\text { Universidade Federal de } \\
\text { Sergipe, Física }\end{array}$ & 2014 & D. \\
\hline
\end{tabular}

Fonte: elaborado pelos autores. ${ }^{3}$

Organizamos aqui os trabalhos dedicados a conhecer concepções e saberes docentes, que investigaram como pensam ou agem os professores, ou a preparar materiais para auxiliar no trabalho e na formação de professores.

Encontramos 8 pesquisas (dissertações) sobre essa temática. Como nas categorias anteriores, a maioria delas está vinculada a programas de pós-graduação da região sudeste, comparecendo em menor número os programas da região sul e nordeste.

${ }^{3}$ Considerada a limitação do número de páginas prevista pelas normas da revista, não apresentamos todas as referências do levantamento (teses e dissertações). 
Nesse grupo de trabalhos, observamos as seguintes abordagens:

1. Silva (2012) analisou como se efetiva o uso das Tecnologias de Informação e Comunicação (TIC) por egressos do mestrado profissional em uma região na Paraíba; Lopes (2012) realizou uma pesquisa com egressos da licenciatura em física, com interesse em verificar como se constituem professores, e a partir da problematização dos saberes docentes, como eles mobilizam as referências subjetivas que aparentam condicionar suas práticas; Silva (2012) analisou a transposição didática, partindo da concepção (modelo epistemológico) adotada por professores de física durante a abordagem do tema Aquecimento Global; Barcellos (2013) intentou compreender o currículo e a relação entre os saberes de física na formação inicial de professores; Mendes (2014) investigou o papel da matematização no ensino de física segundo professores de física, relacionando com a história e filosofia da ciência; Souza (2014) analisou as práticas pedagógicas de professores de física com os princípios teóricometodológicos presentes no ENEM (Exame Nacional do Ensino Médio); Sabino (2015) mapeou os saberes docentes necessários para implementar Física Moderna e Contemporânea (FMC) no ensino médio; Silva Junior (2015) elaborou uma sequência didática de Física Moderna como proposta de trabalho, tendo em vista que esse é um dos temas indicados no currículo do Estado de São Paulo para ser trabalhado na Educação Básica; Garcia (2015) objetivou investigar de que maneira e por quais condicionantes o conhecimento de FMC vem sendo transformado em conhecimento escolar na escola média; Maciel (2016) elaborou material didático, com unidades de ensino potencialmente significativas sobre Astronomia para auxiliar o trabalho do professor de física; já Schmiedecke (2016) elaborou material didático de história da ciência para formação de professores, sendo a elaboração do material acompanhada pela aplicação de questionários respondidos por professores em formação e recémformados.

Observamos que as preocupações se dividem entre as questões relativas à formação inicial, no que diz respeito às questões curriculares e às práticas desenvolvidas e sugeridas aos professores em exercício.

A partir da análise das pesquisas, percebemos novamente a ocupação em problemas pontuais, como a elaboração de materiais didáticos para auxiliar o professor de física, compreender saberes e concepções, ou como pensam e agem os docentes no exercício da profissão. Apesar da importância de tais pesquisas, entendemos que sem uma parceria no âmbito da formação continuada, estas não chegarão de fato aos professores da educação básica. Portanto, novamente sugerimos que as pesquisas, por mais relevantes que sejam, por mais que tratem de temas atuais, não tem conseguido diminuir o fosso existente entre o que é produzido na academia e o que é praticado no ensino de física na escola.

\section{Considerações Finais}

Embora as pesquisas tenham sinalizado há décadas que o ensino de física não tem contribuído de fato com a formação desejada para o cidadão atual, os fatores que envolvem a prática docente impulsionam a perpetuação de um ensino transmissivo, memorístico e matematizado. Concordamos com Moreira (2017) que, embora estejamos no século XXI, permanecemos ensinando quase que exclusivamente a física do século XIX. 
A análise realizada a partir de levantamento bibliográfico, em teses e dissertações disponíveis na BDTD no período de 2012-2017, evidencia que as pesquisas vinculadas à formação do professor de física priorizam as investigações na formação inicial, com grande concentração nas regiões sudeste e sul. Percebemos nas investigações uma preocupação em descrever como fazer, em mostrar como deve ser feito e em investigar o que sabem os futuros professores. Contudo, as parcerias com vistas a um processo de reflexão para superação/ transformação dos desafios circunscritos naquela realidade ainda são tímidas.

As pesquisas no campo da formação continuada mostram-se, prioritariamente, como iniciativas pontuais, baseadas em cursos sobre temas considerados pelos pesquisadores como problemáticos. Notamos a ausência de pesquisas que dão voz aos professores em exercício, que os ouvem para definirem temas e objetos de estudos, evidenciando que os pesquisadores ao se dirigirem ao interlocutor professor, o fazem a partir de falas autoritárias e prescritivas.

Os temas envolvendo a física moderna e contemporânea tem recebido atenção dos pesquisadores, provavelmente por permanecer silenciado pelos professores de física da educação básica. De todo modo, apesar das pesquisas em ensino de física serem realizadas no Brasil há cinquenta anos, os desafios não estão superados. Nossos dados evidenciam que permanece a lacuna entre o que é proferido pela academia e o que pode ser realizado dentro da escola, principalmente por não se estabelecerem pesquisas que envolvam os professores de física em processos efetivos de formação permanente, espaço em que as pesquisas produzidas pela academia seriam notadas e discutidas no processo de reflexão e compreensão da realidade.

Concluímos, que as pesquisas desenvolvidas no âmbito da formação de professores deveriam se preocupar com os seus efeitos na transformação da realidade. No que pode ser feito na escola e tecer uma parceria efetiva entre escola e universidade. Esse se vislumbra um caminho para dar voz às pesquisas e fazerem-se ouvidos os professores de física.

Se as pesquisas em ensino de física têm, implícita ou explicitamente o objetivo de transformar a realidade da escola, em especial da escola pública, devem passar por mudanças em muitos aspectos. Em especial, destacamos a necessidade de fortalecer parcerias entre pesquisadores em ensino e professores da educação básica, para que desta aproximação resulte uma maior compreensão pelos pesquisadores dos reais problemas da escola e, do outro lado, uma maior incorporação dos resultados de pesquisa no redirecionamento das práticas. Essas mudanças passam necessariamente por substituição de discursos prescritivos (o professor deve, o professor tem que) ainda fortes nas pesquisas, por discursos que coloquem os professores da educação básica como autores da própria prática, construtores de currículos, protagonistas nos processos de ensino realizados nas e pelas escolas.

\section{Referências}

ANJOS, A. J. S. Pesquisa em ensino de física e sala de aula: uma reflexão necessária. Caderno de Física da UEFS, Feira de Santana, v. 11, n. 1-2, p. 7-12, 2013. Disponível em: http://dfisweb.uefs.br/caderno/ vol11n12/Artigo01AJorge.pdf. Acesso em: 20 ago. 2020.

BAKHTIN, M. M. Estética da criação verbal. 4. ed. São Paulo: Martins Fontes, 2003.

CACHAPUZ, A. F. Educação em ciências: caminhos percorridos e dinâmicas de mudança. In: MAGALHÃES JUNIOR, C. A. O.; LORENCINI JUNIOR, A.; CORAZZA, M. J. (org.). Ensino de ciências: múltiplas perspectivas, diferentes olhares. Curitiba: CRV, 2014. p. 173-198. 
CAMILLO, J.; MATTOS, C. R. A experimentação no ensino de ciências: reflexões a partir da teoria da atividade. In: MAGALHÃES JÚNIOR, C. A. O.; LORENCINI JÚNIOR, A.; CORAZZA, M. J. (org.). Ensino de ciências: múltiplas perspectivas, diferentes olhares. Curitiba: CRV, 2014. p. 123-154.

CARVALHO, A. M. P.; SASSERON, L. H. Ensino e aprendizagem de física no ensino médio e a formação de professores. Estudos Avançados, São Paulo, v. 32, n. 94, p. 43-55, 2018.

CARVALHO, A. M. P.; GIL-PÉREZ, D. Formação de professores de ciências: tendências e inovações. 10. ed. São Paulo: Cortez, 2011.

CHAVES, S. N. Por uma nova epistemologia da formação docente: o que diz a literatura e o que fazem os formadores. In: SCHNETZLER, R. P.; ARAGÃO, R. M. R. (org.). Ensino de ciências: fundamentos e abordagens. Campinas: R. Vieira, 2000. p. 42-59.

KUSSUDA, S. R.; NARDI, R. Falta de professores licenciados em física no ensino público do estado de São Paulo: uma relação entre a distribuição geográfica das universidades e as vagas no magistério do ensino médio. In: ENCONTRO NACIONAL DE PESQUISAS EM EDUCAÇÃO EM CIÊNCIAS, 10., 2015, Águas de Lindóia. Anais [...]. Águas de Lindóia: ABRAPEC, 2015. p. 1-8.

KUSSUDA, S. R.; NARDI, R. Motivações para a permanência ou abandono do magistério segundo licenciados em física de uma universidade pública. In: SIMPÓSIO NACIONAL DE ENSINO DE FÍSICA, 20., 2013, São Paulo. Anais [...]. São Paulo: SBF, 2013. p. 1-7.

LEONE, N. M.; LEITE, Y. U. F. O início da carreira docente: implicações à formação inicial de professores. Revista Eletrônica Pesquiseduca, Santos, v. 3, n. 6, p. 236-259, 2011. Disponível em: http://periodicos.unisantos.br/index.php/pesquiseduca/article/view/195. Acesso em: 20 ago. 2020.

MAGALHÃES JÚNIOR, C. A. O.; PIETROCOLA, M. Atuação de professores formados em licenciatura plena em ciências. Alexandria: revista de educação em ciência e tecnologia, Florianópolis, v. 4, n. 1, p. 175-198, 2011

MARANDINO, M. A pesquisa educacional e a produção de saberes nos museus de ciência. História, Ciências, Saúde - Manguinhos, Rio de Janeiro, v. 12, sup., p. 161-81, 2005.

MARCELO, C. Desenvolvimento profissional docente: passado e futuro. Sísifo: revista de ciências da educação, Lisboa, n. 8, p. 7-22, 2009.

MARTÍNEZ-AZNAR, M. M.; RODRÍGUEZ-ARTECHE, I.; GÓMEZ-LESARRI, P. La resolución de problemas profesionales como referente para la formación inicial del profesorado de física y química. Revista Eureka sobre Enseñanza y Divulgación de las Ciencias, Cádiz, v. 14, n. 1, p. 162-180, 2016. Disponível em: https://revistas.uca.es/index.php/eureka/article/view/3017. Acesso em: 28 jan. 2019.

MARTINS, J. A pesquisa qualitativa. In: FAZENDA, I. (org.). Metodologia da pesquisa educacional. 12. ed. São Paulo: Cortez, 2010. p. 51-63.

MOREIRA, M. A. Ensino de física no Brasil: retrospectivas e perspectivas. Revista Brasileira de Ensino de Física, São Paulo, v. 22, n. 1, p. 94-99, 2000. Disponível em: http://www.sbfisica.org.br/rbef/pdf/ v22_94.pdf. Acesso em: 28 ago 2020.

MOREIRA, M. A. Grandes desafios para o ensino da física na educação contemporânea. Revista do Professor de Física, Brasília, v. 1, n. 1, p. 1-13, 2017. DOI: https://doi.org/10.26512/rpf.v1i1.7074.

NARDI, R. (org). Ensino de ciências e matemática, l: temas sobre a formação de professores. São Paulo: Cultura Acadêmica, 2009.

NARDI, R.; ALMEIDA, M. J. P.M.; KUSSUDA, S. R.; COSTA, A.C.S. A pesquisa em ensino de ciências e o ensino de sala de aula: memórias de professores que atuaram nas últimas décadas. In: ENCONTRO NACIONAL DE PESQUISAS EM EDUCAÇÃO EM CIÊNCIAS, 7., 2009, Florianópolis. Anais [...].

Florianópolis: ABRAPEC, 2009. p. 1-8. 
PENA, F. L. A.; FREIRE JÚNIOR, O. Sobre a modernização do ensino de física no Brasil (1960 - 1979). In: ENCONTRO NACIONAL DE PESQUISAS EM EDUCAÇÃO EM CIÊNCIAS, 4., 2003, Bauru. Anais [...]. Bauru: ABRAPEC, 2003.

ROLDÃO, M. C. Função docente: natureza e construção do conhecimento profissional. Revista Brasileira de Educação, Rio de Janeiro, v. 12, n. 34, p. 94-103, 2007.

RUIZ, A. I.; RAMOS, M. N.; HINGEL, M. Escassez de professores no ensino médio: propostas estruturais e emergenciais. Brasília: Câmara de Educação Básica, 2007. Disponível em: http://portal.mec.gov.br/ cne/arquivos/pdf/escassez1.pdf. Acesso em: 24 ago. 2020.

SASSERON, L. H. Alfabetização científica e documentos oficiais brasileiros: um diálogo na estruturação do ensino da física. In: CARVALHO, A. M. P.; RICARDO, E. C.; SASSERON, L. H.; ABIB, M. L. V.; PIETROCOLA, M. Ensino de física. São Paulo: Cengage Learning, 2010. p. 1-28.

SCHNETZLER, R. P. O professor de ciências: problemas e tendências de sua formação. In: SCHNETZLER, R. P.; ARAGÃO, R. M. R. (org.). Ensino de ciências: fundamentos e abordagens. Campinas: R. Vieira, 2000. p. 12-39.

SILVA, M. O habitus professoral: o objeto dos estudos sobre o ato de ensinar na sala de aula. Revista Brasileira de Educação, Rio de Janeiro, n. 29, p. 152-163, 2005.

TARDIF, M. Saberes docentes e formação profissional. 10. ed. Petrópolis: Vozes, 2010.

VOLÓCHINOV, V. Marxismo e filosofia da linguagem: problemas fundamentais do método sociológico na ciência da linguagem. São Paulo: Editora 34, 2017. 